\title{
The effectiveness of interprofessional education programs for medical, nursing, and pharmacy students
}

\author{
Han Jung ${ }^{1}$ Kwi Hwa Park' ${ }^{2}$ Yul Ha $\mathrm{Min}^{3}$ and Eunhee $\mathrm{Ji}^{4}$ \\ Departments of ${ }^{1}$ Urology and ${ }^{2}$ Medical Education, Gachon University College of Medicine, ${ }^{3}$ Gachon University \\ College of Nursing, and ${ }^{4}$ Gachon University College of Pharmacy, Incheon, Korea
}

Purpose: This study is to develop an interprofessional education (IPE) program for medical, nursing, and pharmacy students and to analyze the effectiveness.

Methods: Subjects consisted of 116 students (41 medical, 46 nursing, and 29 pharmacy students) enrolled in their final year. Subjects were randomly assigned to either the intervention group or the control group, with 58 in each group. A pretest-posttest control group design was used. The program was operated for a single day, and consisted of small-group activities and role-play. We utilized the following tools: Perceptions towards Interprofessional Education (PIPE), Self-Efficacy for Interprofessional Experiential Learning (SEIEL), and Perception towards Interprofessional Competency (PIC). We used t-test and analysis of covariance for analysis.

Results: The PIPE tool revealed that the scores of the intervention group were significantly higher than those of the control group $(p=0.000)$. The result was the same when the scores were categorized into the groups medical students $(p=0.001)$, nursing students $(p=0.000)$, and pharmacy students $(p=0.005)$. The SEIEL study also indicated the intervention group scored significantly higher than the control group $(p=0.000)$. However, pharmacy students did not reveal significant $(p=0.983)$. The intervention group scored significantly higher than the control group in the PIC. A concluding survey of the intervention group indicated that most students were satisfied with the IPE program.

Conclusion: We hope this study will provide useful information for designing and improving IPE programs in other universities.

Key Words: Medical education, Medical students, Nursing students, Pharmacy students, Interprofessional education

\section{Introduction}

Just as healthcare teams should have expertise in their respective fields, they should also communicate and collaborate with other professionals to provide optimal patient-centered care. Effective healthcare teams contribute to increased satisfaction among patients, reduction in medical expenses, reduction in the rate of medical errors, and the improvement of overall medical care [1-3]. Ultimately, this effectiveness promotes the safety of patients. To this end, health professions have begun to take interest in interprofessional education (IPE).

In IPE programs, educators and learners from two or more health professions and professional health students jointly create and foster a collaborative learning environment [4]. IPE programs require the participation
Received: March 23, 2020 • Revised: April 22, 2020 • Accepted: April 24, 2020 Corresponding Author: Kwi Hwa Park (https://orcid.org/0000-0002-0008-2400) Department of Medical Education, Gachon University College of Medicine, 38-13 Dokjeom-ro 3beon-gil, Namdong-gu, Incheon 21565, Korea Tel: +82.32.458.2635 Fax: +82.32.421.5537 email: ghpark@gachon.ac.kr
Korean J Med Educ 2020 Jun; 32(2): 131-142.

https://doi.org/10.3946/kjme.2020.161

eISSN: 2005-7288

(C) The Korean Society of Medical Education. All rights reserved. This is an open-access article distributed under the terms of the Creative Commons Attribution Non-Commercial License (http:// creativecommons.org/licenses/by-nc/3.0/), which permits unrestricted non-commercial use, distribution, and reproduction in any medium, provided the original work is properly cited. 
of an educator who understands how health professionals should work together in interprofessional care, engaging students in a reflective interaction with one another [3]. IPE is an ideal method for understanding different professional roles, values, and perspectives, and for teaching collaboration, teamwork, and leadership within care teams [5,6]. Students often learn independently about other health professions in the field, after graduating from college [7]. However, it is not easy to improve one's perception and attitude toward other professions within the healthcare system [8]. Therefore, it is critical to educate students of healthcare to develop competency in interprofessional collaboration as they enter the healthcare field following graduation.

The guidelines for IPE were published in 1973 by World Health Organization [4], and IPE programs have been implemented in the United States, Canada, and many European countries including the United Kingdom [9]. A study conducted in the United States reported that 14 out of 16 medical schools were implementing IPE programs, 93\% of which were a collaboration among schools of medicine and nursing, with 57\% also including schools of pharmacy [10]. There are various education models of IPE such as lectures, community-based experience, and simulation [3]. The primary methods for IPE include small-group activities, simulation-based learning, games and role play [10], and case-based discussions [11]. Performance in IPE is evaluated based on small group participation (32\%), a group project (32\%), and reflective writing (13\%) [11]. The outcome of IPE is measured in terms of the changes in student responses, skills, knowledge, attitude, and behavior [8].

IPE programs in Korea operate in stark contrast to programs in Western countries. Recent studies examined the current condition of IPE implementation in medical schools [12] and perception of health care professionals and professors [7,12-14]. According to these studies,
$14.8 \%$ of professors in schools of medicine, nursing, and pharmacy were familiar with IPE and only $4.2 \%$ had experienced IPE. As such, the perception of IPE remains to be lacking. A recent survey about IPE implementation indicated that 14 out of 30 medical schools were reportedly providing medical students with lectures on the unique nature and responsibilities of other health professions or running programs fostering hands-on experience within other health professions [12]. However, the study did not mention whether the lectures were provided simultaneously to other students of healthcare or whether there was interaction among them. IPE programs have been implemented among students in the school of medicine, nursing, and oriental medicine [15]. As indicated in the above examples, the research on IPE in Korea remains undeveloped. Moreover, it is challenging to find studies that have designed IPE programs and have presented outcomes.

It has been reported that students who have participated in IPE programs experienced positive effects such as improved understanding of other professional healthcare roles, positive attitude toward IPE, and increased readiness for IPE $[16,17]$. Unfortunately, the majority of Korean students do not possess awareness of the importance of IPE programs, nor do they have opportunities to experience them [18]. Therefore, it is imperative that medical schools develop and vitalize IPE programs that can improve the collaboration and communication among healthcare students and can improve effective interprofessional attitudes.

To this end, we aimed to develop and implement an IPE program for medical, nursing, and pharmacy students. In addition, we endeavored to analyze the effect of the program and the changes in students by comparing the participant and non-participant groups. The specific research questions are as follows. (1) Is 
there a difference in perceptions towards IPE between the intervention and control group? (2) Is there a difference in self-efficacy for interprofessional experiential learning between the intervention and control group? (3) Is there a difference in perception towards interprofessional competency between the intervention and control group? (4) How is the mediation group satisfaction with the IPE program?

\section{Methods}

\section{Participants}

For this study, 116 students with no prior IPE experience were recruited among final-year students. The intervention group and the control group each included 58 students. In the intervention group, 21 were medical students (36.2\%), 23 were nursing students (39.7\%), and 14 were pharmacy students (24.1\%). Nineteen of them were male (32.8\%), and 39 were female (67.2\%). The control group consisted of 20 medical students (34.4\%), 23 nursing students (39.7\%), and 15 medical students (25.9\%). Out of 58 students, 21 were male (36.2\%) and 37 were female (63.8\%).

\section{Study design}

We used a pretest-posttest control group design. Students who authorized consent to the survey were randomly assigned to either the intervention group or the control group by random drawing lots. The ratio of the group was 1:1. Before implementing the IPE program, the intervention group and the control group were given the pretest survey. The IPE program was implemented in the intervention group, and both the intervention and control groups were given the posttest survey following the conclusion of the program. Only the intervention group was given an additional survey surveying their satisfaction with the program.

\section{Procedure of IPE program development and implementation}

With the consultation of two professors from schools of medicine, one professor from a school of nursing, one professor from a school of pharmacy, and one medical education specialist, we developed an IPE program. First of all, the program was designed to help students understand the purpose of IPE and different roles of health professionals. To do so, we engaged the participants in small-group activities to discuss the roles and expectations for doctors, nurses, and pharmacists. Second, we developed a scenario simulating a medication error, as a likely case of conflict that could occur due to the absence of interprofessional communication within healthcare practices. Students were led to detect problems and derive solutions through role-play. The plot of the scenario featured a medication error caused by the incorrect dispensation of medication by a pharmacist, followed by the negligence of a nurse or doctor to verify the prescription. The program was implemented within a 6-hour period of one single day. The outcomes and content of the IPE program are presented in Figs. 1 and 2.

\section{Instruments}

\section{1) Perceptions towards Interprofessional Education}

Seventeen questions that measure perceptions towards IPE were developed after reviewing relevant studies [19] and verifying the content for validity with the consultation of two IPE experienced medical education specialists. The collected data were deemed suitable for factor analysis as the standardized goodness of fit on the Kaiser-Meyer-Oklin (KMO) test showed correlation at 0.929 and Bartlett's test showed each variable was 
Fig. 1. Learning Outcomes of the IPE Program

\begin{tabular}{l|l|l|}
\hline \multicolumn{2}{|c|}{ Learning outcomes } \\
\hline $\begin{array}{l}\text { 1. The students can understand the } \\
\text { purpose of IPE and explain its } \\
\text { necessity. }\end{array}$ & $\begin{array}{l}\text { 2. The students can explain their } \\
\text { own roles and the various roles of } \\
\text { other healthcare practices. }\end{array}$ & $\begin{array}{l}\text { 3. The students can derive solutions } \\
\text { based on the diagnosis of conflict } \\
\text { in interprofessional communication } \\
\text { that occurs within healthcare } \\
\text { practice. }\end{array}$ \\
\hline
\end{tabular}

IPE: Interprofessional education.

Fig. 2. Contents of the IPE Program

\begin{tabular}{|l|l|l|}
\hline \multicolumn{1}{|c|}{ Contents } & Running time (min) & $\begin{array}{c}\text { Educational } \\
\text { method }\end{array}$ \\
\hline Pretest & 10 \\
\hline $\begin{array}{l}\text { Orientation } \\
\text { - Description of the program: purpose and flow }\end{array}$ & 5 & Lecture \\
\hline $\begin{array}{l}\text { Role-play simulating a medication error } \\
\text { - Orientation } \\
\text { - Role-play: under the guidance of the role-play instructor, } \\
\text { participate in a role-play based on the medication error scenario } \\
\text { - Discussion \& debriefing }\end{array}$ & Role-play \\
\hline $\begin{array}{l}\text { Break } \\
\text { IPE and the importance of patient's safety }\end{array}$ & 120 \\
\hline $\begin{array}{l}\text { Roles and expectations for doctors, nurses, and pharmacists } \\
\text { - Discussion the roles and expectation for each professionals, } \\
\text { following questions and feedback }\end{array}$ & 20 \\
\hline \begin{tabular}{l} 
Completion and posttest \\
\hline
\end{tabular} & 10 \\
\hline
\end{tabular}

IPE: Interprofessional education.

independent $\left(\chi^{2}=1,257.538, \mathrm{df}=66, \mathrm{p}=0.000\right)$. In the process of factor analysis, we excluded five items that manifested factor loadings inconsistent with other factors or appeared to be loaded on plural factors. Ultimately, we derived 12 items that consisted of three factors. Factor 1 was labeled as the effectiveness of IPE (six items); factor 2 was labeled as preference for IPE (four items); and factor 3 was labeled as the importance of IPE (two items). The reliability of each sub-factor was indicated good by Cronbach's $\alpha$ at 0.936, 0.914, and 0.836 .

\section{2) The Self-Efficacy for Interprofessional $\mathrm{Ex}^{-}$ periential Learning}

To examine the changes in self-efficacy of the participants, we formed a questionnaire with 15 items reflecting the situation in Korea, by revising SelfEfficacy for Interprofessional Experiential Learning, which was the criteria developed by Mann et al. [20]. The collected data were found to be suitable for factor analysis as the standardized goodness of fit on $\mathrm{KMO}$ showed correlation at 0.934 and Bartlett's test showed that all variables were independent $\left(\chi^{2}=1,364.677, \mathrm{df}=\right.$ 66, $\mathrm{p}=0.000$ ). In the process of factor analysis, we excluded three items that appeared to be loaded on other factors. Eventually, we derived 12 items that consisted of two factors. Seven items for interprofessional feedback and five items for interprofessional interaction were utilized. The reliability of each sub-factor was indicated to be good by Cronbach's $\alpha$ at 0.947 and 0.921 .

\section{3) Perception towards Interprofessional Competency}

To examine the changes in the perception of students toward interprofessional competency, we used the nine questions presented in the interprofessional competency survey in a study of Baek et al. [18]. Of none categories 
of competency, we selected five that match the expected outcome of this program, including collaborative leadership, communication skills, interprofessional conflict solving skills, understanding the roles of other professionals in interprofessional collaboration, and understanding their own roles within the collaborative practice in interprofessional collaboration.

\section{4) Satisfaction with the program}

To evaluate the satisfaction of participants with the IPE program, we developed a separate questionnaire of 15 items based on Cronbach's $\alpha$ of 0.959 .

\section{Ethical considerations}

This study was approved by the Gil Medical Center Institutional Review Board of Gachon University (IRB approval no., GCIRB-2018-150). The purpose of the study was elucidated and participant consent was obtained prior to starting the surveys.

\section{Data analysis}

First, t-test was conducted to prove the effectiveness of the IPE program by comparing groups. Second, analysis of covariance (ANCOVA) was performed when the homogeneity between groups was not ensured. Finally, the mean and the standard deviation were calculated to gauge program satisfaction.

\section{Results}

\section{Analysis of IPE program effectiveness}

\section{1) Perceptions towards Interprofessional Education}

To test the homogeneity between the intervention group and the control group, t-test was conducted based on the recorded pretest scores. The results revealed a significant difference, rendering no homogeneity $(\mathrm{p}>0.05)$. Subsequently, to minimize the effect of the Perceptions towards Interprofessional Education pretest scores on the posttest, and to measure the effectiveness of the IPE program more accurately, we performed ANCOVA after calculating the mean and the standard deviation (Table 1) and controlling the pretest score with covariate (Table 2). The result revealed a significant variance between the intervention and control groups in terms of the sub-factors of perception towards IPE (the

Table 1. The Mean and the Standard Deviation on PIPE

\begin{tabular}{lllcc}
\hline \multicolumn{1}{c}{ Students } & \multicolumn{1}{c}{ Variable } & Pre/post & Intervention group & Control group \\
\hline All students & The importance of IPE & Pretest & $4.05 \pm 0.77$ & $3.94 \pm 0.83$ \\
& & Posttest & $4.36 \pm 0.63$ & $3.76 \pm 0.81$ \\
& The preference for IPE & Pretest & $3.45 \pm 1.00$ & $3.29 \pm 0.93$ \\
& & Posttest & $4.11 \pm 0.84$ & $3.34 \pm 0.93$ \\
& \multirow{2}{*}{ The effectiveness of IPE } & Pretest & $3.93 \pm 0.71$ & $3.75 \pm 0.76$ \\
& & Posttest & $4.40 \pm 0.60$ & $3.76 \pm 0.82$ \\
Total of PIPE & Pretest & $3.79 \pm 0.75$ & $3.63 \pm 0.76$ \\
& & Posttest & $4.30 \pm 0.64$ & $3.64 \pm 0.79$ \\
Nursing students & Total of PIPE & Pretest & $3.72 \pm 0.81$ & $3.13 \pm 0.75$ \\
& & Posttest & $4.18 \pm 0.64$ & $3.17 \pm 0.87$ \\
Pharmacy students & Total of PIPE & Pretest & $4.01 \pm 0.49$ & $3.70 \pm 0.57$ \\
& & Posttest & $4.53 \pm 0.50$ & $3.80 \pm 0.53$ \\
& Total of PIPE & Pretest & $3.53 \pm 0.95$ & $4.19 \pm 0.60$ \\
& & Posttest & $4.08 \pm 0.76$ & $4.15 \pm 0.65$ \\
\hline
\end{tabular}

Data are presented as mean \pm standard deviation.

PIPE: Perceptions towards Interprofessional Education, IPE: Interprofessional education. 
importance of IPE, the preference for IPE, and the effectiveness of IPE). As for the general perception towards the IPE, there was a significant difference between the two groups on the posttest $(\mathrm{p}=0.000)$. The average posttest score for the intervention group was significantly higher than that of the control group.
Moreover, the average score of the intervention group increased more greatly on the posttest than did the score of the control group (Table 1). When the test scores were categorized by the participant's major and sorted by medical students ( $\mathrm{p}=0.001)$, nursing students $(\mathrm{p}=0.000)$, and pharmacy students $(\mathrm{p}=0.005)$ respectively, the

Table 2. Analysis of Covariance on PIPE

\begin{tabular}{|c|c|c|c|c|c|c|c|}
\hline Students & Variable & Source & SS & $\mathrm{df}$ & MS & F-value & $\mathrm{p}$-value \\
\hline \multirow[t]{12}{*}{ All students } & \multirow[t]{3}{*}{ The importance of IPE } & Pretest & 35.922 & 1 & 35.922 & 183.440 & 0.000 \\
\hline & & Group & 6.936 & 1 & 6.936 & 35.420 & 0.000 \\
\hline & & Error & 21.345 & 109 & 0.196 & & \\
\hline & \multirow[t]{3}{*}{ The preference for IPE } & Pretest & 47.360 & 1 & 47.360 & 130.885 & 0.000 \\
\hline & & Group & 11.639 & 1 & 11.639 & 32.166 & 0.000 \\
\hline & & Error & 39.441 & 109 & 0.362 & & \\
\hline & \multirow[t]{3}{*}{ The effectiveness of IPE } & Pretest & 29.649 & 1 & 29.649 & 123.747 & 0.000 \\
\hline & & Group & 7.441 & 1 & 7.441 & 31.058 & 0.000 \\
\hline & & Error & 25.876 & 108 & 0.240 & & \\
\hline & \multirow[t]{3}{*}{ Total of PIPE } & Pretest & 36.180 & 1 & 36.180 & 200.175 & 0.000 \\
\hline & & Group & 8.118 & 1 & 8.118 & 44.917 & 0.000 \\
\hline & & Error & 19.520 & 108 & 0.181 & & \\
\hline \multirow[t]{3}{*}{ Medical students } & \multirow[t]{3}{*}{ Total of PIPE } & Pretest & 13.089 & 1 & 13.089 & 52.416 & 0.000 \\
\hline & & Group & 2.965 & 1 & 2.965 & 11.874 & 0.001 \\
\hline & & Error & 9.489 & 38 & 0.250 & & \\
\hline \multirow[t]{3}{*}{ Nursing students } & \multirow[t]{3}{*}{ Total of PIPE } & Pretest & 5.039 & 1 & 5.039 & 33.914 & 0.000 \\
\hline & & Group & 3.180 & 1 & 3.180 & 21.400 & 0.000 \\
\hline & & Error & 6.241 & 42 & 0.149 & & \\
\hline \multirow[t]{3}{*}{ Pharmacy students } & \multirow[t]{3}{*}{ Total of PIPE } & Pretest & 8.564 & 1 & 8.564 & 59.187 & 0.000 \\
\hline & & Group & 1.406 & 1 & 1.406 & 9.714 & 0.005 \\
\hline & & Error & 3.183 & 22 & 0.145 & & \\
\hline
\end{tabular}

PIPE: Perceptions towards Interprofessional Education, SS: Sum of squares, df: Degree of freedom, MS: Mean squares, IPE: Interprofessional education.

Table 3. Analysis on the SElEL

\begin{tabular}{|c|c|c|c|c|c|c|c|c|}
\hline \multirow{2}{*}{ Students } & \multirow{2}{*}{ Variable } & \multirow{2}{*}{ Group } & \multicolumn{3}{|c|}{ Pretest } & \multicolumn{3}{|c|}{ Posttest } \\
\hline & & & Mean \pm SD & $\mathrm{t}$-value & $\mathrm{p}$-value & Mean $\pm S D$ & $\mathrm{t}$-value & $p$-value \\
\hline \multirow{6}{*}{ All students } & Interaction & Intervention & $3.51 \pm 0.70$ & 0.552 & 0.582 & $4.10 \pm 0.65$ & -3.641 & 0.000 \\
\hline & & Control & $3.58 \pm 0.71$ & & & $3.66 \pm 0.61$ & & \\
\hline & Feedback & Intervention & $3.57 \pm 0.74$ & -0.642 & 0.522 & $4.10 \pm 0.65$ & -4.090 & 0.000 \\
\hline & & Control & $3.48 \pm 0.78$ & & & $3.56 \pm 0.75$ & & \\
\hline & Total of SEIEL & Intervention & $3.55 \pm 0.70$ & -0.174 & 0.862 & $4.10 \pm 0.64$ & -4.047 & 0.000 \\
\hline & & Control & $3.52 \pm 0.72$ & & & $3.60 \pm 0.67$ & & \\
\hline \multirow[t]{2}{*}{ Medical students } & Total of SEIEL & Intervention & $3.80 \pm 0.73$ & -1.245 & 0.221 & $4.12 \pm 0.62$ & -2.688 & 0.011 \\
\hline & & Control & $3.52 \pm 0.72$ & & & $3.53 \pm 0.77$ & & \\
\hline \multirow[t]{2}{*}{ Nursing students } & Total of SEIEL & Intervention & $3.30 \pm 0.64$ & 0.000 & 1.000 & $4.21 \pm 0.50$ & -4.187 & 0.000 \\
\hline & & Control & $3.30 \pm 0.68$ & & & $3.53 \pm 0.60$ & & \\
\hline \multirow[t]{2}{*}{ Pharmacy students } & Total of SEIEL & Intervention & $3.56 \pm 0.68$ & 1.184 & 0.247 & $3.89 \pm 0.83$ & -0.022 & 0.983 \\
\hline & & Control & $3.86 \pm 0.69$ & & & $3.89 \pm 0.56$ & & \\
\hline
\end{tabular}

SEIEL: Self-Efficacy for Interprofessional Experiential Learning, SD: Standard deviation. 
posttest scores exhibited a significant difference between the intervention group and the control group, with a greater increase in the average score for the intervention group on the posttest.

\section{2) The Self-Efficacy for Interprofessional $\mathrm{Ex}^{-}$ periential Learning}

To test the homogeneity between the intervention group and the control group, $\mathrm{t}$-test was conducted based on the pretest scores. As a result, homogeneity was found (Table 3). The result of conducting the posttest indicated that the intervention group scored significantly higher than the control group did in the overall self-efficacy ( $\mathrm{t}=-4.047, \mathrm{p}=0.000)$ as well as in all subfactors of IPE self-efficacy, including interprofessional interaction $(\mathrm{t}=-3.641, \mathrm{p}=0.000)$ and interprofessional feedback ( $\mathrm{t}=-4.090, \mathrm{p}=0.000$ ) (Table 3 ). In addition, the intervention group showed a significantly increased self-efficacy score from the pretest to the posttest $(\mathrm{p}=0.000)$, whereas the control group did not reveal significant improvement $(\mathrm{p}>0.05)$. When the scores were analyzed based on the major (schools of medicine, nursing, and pharmacy), the posttest scores of the medical students $(\mathrm{p}=0.011)$ and the nursing students $(p=0.000)$ in the intervention group were significantly high in overall self-efficacy. In contrast, pharmacy students did not achieve a significant change in the posttest score $(\mathrm{p}=0.983)$.

\section{3) Perception towards Interprofessional $\mathrm{Com}^{-}$ petency}

T-test was conducted to evaluate and confirm homogeneity between the intervention group and the control group (Table 4). Posttest results revealed that the intervention group scored significantly higher than the control group in the level of competency awareness in collaborative leadership ( $\mathrm{t}=-2.445, \mathrm{p}=0.016)$, communication skills $(\mathrm{t}=-2.273, \mathrm{p}=0.025)$, interprofessional conflict solving skills $(\mathrm{t}=-2.028, \mathrm{p}=0.045)$, understanding the roles of other professionals $(t=-3.777, p=0.000)$, and understanding their own roles within the collaborative practice $(\mathrm{t}=-2.943, \mathrm{p}=0.004)$.

\section{Satisfaction with the IPE program}

The intervention group was administered a second survey for the purpose of measuring their level of satisfaction with the program (Table 5). The results indicated that most participants were satisfied with the program (average score $>4.0$ out of 5 points). Students rated the duration of the program relatively unsatisfactory (average score $=3.71$ points).

Students openly commented that strengths of the

Table 4. Analysis on the Perception towards Interprofessional Competency

\begin{tabular}{|c|c|c|c|c|c|c|c|}
\hline \multirow{2}{*}{ Interprofessional competency } & \multirow{2}{*}{ Group } & \multicolumn{3}{|c|}{ Pretest } & \multicolumn{3}{|c|}{ Posttest } \\
\hline & & Mean \pm SD & t-value & $p$-value & Mean \pm SD & t-value & $\mathrm{p}$-value \\
\hline \multirow[t]{2}{*}{ Collaborative leadership } & Intervention & $3.31 \pm 0.94$ & -0.696 & 0.488 & $3.79 \pm 0.87$ & -2.445 & 0.016 \\
\hline & Control & $3.19 \pm 0.93$ & & & $3.41 \pm 0.79$ & & \\
\hline \multirow[t]{2}{*}{ Communication skills } & Intervention & $3.62 \pm 0.86$ & -1.316 & 0.191 & $3.95 \pm 0.80$ & -2.273 & 0.025 \\
\hline & Control & $3.41 \pm 0.84$ & & & $3.61 \pm 0.76$ & & \\
\hline \multirow[t]{2}{*}{ Conflict solving skills } & Intervention & $3.45 \pm 0.84$ & 0.201 & 0.841 & $3.93 \pm 0.79$ & -2.028 & 0.045 \\
\hline & Control & $3.48 \pm 0.99$ & & & $3.61 \pm 0.88$ & & \\
\hline \multirow{2}{*}{$\begin{array}{l}\text { Understanding the roles of other } \\
\text { professionals }\end{array}$} & Intervention & $3.59 \pm 0.96$ & -1.102 & 0.273 & $4.19 \pm 0.71$ & -3.777 & 0.000 \\
\hline & Control & $3.40 \pm 0.89$ & & & $3.65 \pm 0.81$ & & \\
\hline \multirow{2}{*}{$\begin{array}{l}\text { Understanding their own roles within } \\
\text { the collaborative practice }\end{array}$} & Intervention & $3.79 \pm 0.85$ & -1.087 & 0.279 & $4.19 \pm 0.71$ & -2.943 & 0.004 \\
\hline & Control & $3.62 \pm 0.86$ & & & $3.78 \pm 0.77$ & & \\
\hline
\end{tabular}

SD: Standard deviation. 
Table 5. Satisfaction with the IPE Program

\begin{tabular}{lcc}
\hline \multicolumn{1}{c}{ Items } & No. of participants & Mean \pm SD \\
\hline 1. The purpose of the program was clearly explained to the students. & 51 & $4.00 \pm 0.959$ \\
2. It was desirable to implement the program for final year students. & 51 & $4.02 \pm 1.029$ \\
3. The program featured an adequate amount of running time. & 51 & $3.71 \pm 1.082$ \\
4. The overall program was well designed. & 51 & $4.02 \pm 0.860$ \\
5. The objective of the program was achieved. & 51 & $4.06 \pm 0.904$ \\
6. The role-play was an effective tool for achieving some program objectives. & 51 & $4.18 \pm 0.817$ \\
7. The program was helpful for understanding the importance of teamwork. & 50 & $4.46 \pm 0.646$ \\
8. The program was helpful for understanding the value of IPE. & 51 & $4.18 \pm 0.817$ \\
9. The program was helpful for understanding the roles and responsibilitiesof other health & 51 & $4.45 \pm 0.642$ \\
professionals. & & \\
10. The program was helpful for understanding the competency required for collaboration and & 51 & $4.43 \pm 0.671$ \\
communication among doctors, nurses, and pharmacists. & 51 & $4.24 \pm 0.737$ \\
11. The instructors played a role in promoting collaboration among healthcare students. & 50 & $4.24 \pm 0.716$ \\
12. The instructors provided useful feedback to students. & 51 & $4.27 \pm 0.896$ \\
13. Overall, I am satisfied with the program. & 51 & $4.31 \pm 0.836$ \\
14. This program should be provided to future students. & 51 & $4.24 \pm 0.907$ \\
15. I will participate in other programs with similar objectives.
\end{tabular}

IPE: Interprofessional education, SD: Standard deviation.

program included the opportunity to engage in discussions with students of other majors, identifying with the perspectives of others, learning the value of the roles of others, and learning through a participationcentered program. Students commented that limitations of the program included insufficient running time and room for improvement regarding the simulation exercise.

\section{Discussion}

Even though IPE in the healthcare field is drawing more attention and the awareness for its need is growing, actual cases of implementing the program are rare. In this context, the present study developed an IPE program that engages students of medicine, nursing, and pharmacy and analyzed the effectiveness of the program.

At the completion of the program, the intervention group scored higher than the control group on the posttest in the importance of IPE, preference, and effectiveness. These results support the findings of previous studies that reported positive effects of participation in IPE programs on the student responses and attitudes toward IPE $[8,16,21,22]$. The results were consistent among students of medicine, nursing, and pharmacy, irrespective of the participants' majors. In other words, the IPE program helped all participants (medical, nursing, and pharmacy students) improve their perception of IPE. This program was proven to be effective even for medical students who tended to have negative perceptions and attitudes towards IPE compared to other students of healthcare professions [23].

After implementing the program, the intervention group improved significantly on their Self-Efficacy for Interprofessional Experiential Learning score, surpassing the score of the control group. This proves the program can improve student confidence in interprofessional learning. This result aligns with the conclusion of Ivey et al. [24] among students of physical therapy and occupational therapy. When each profession was viewed individually, however, pharmacy students did not show any changes in self-efficacy, regardless of their participation in the program. Unlike Western countries, the clinical pharmacy system has not been vitalized in 
South Korea, although the value of pharmaceutical education is increasing as the curriculum is continually revised [25]. Additionally, pharmacists are rarely viewed as part of the healthcare team in the clinical field [25]. The current status of curriculum and attitudes within the healthcare industry may have affected the self-efficacy of the pharmacy students who participated in this program. Until recently, IPE has been a research topic only centering on schools of medicine and nursing, but, in recent years, the scope of research centering on the school of pharmacy has grown [26]. Therefore, it is crucial to consider adequate incorporation of IPE into the pharmaceutical curriculum in South Korea.

Results of the posttest revealed the perception of the intervention group towards interprofessional competency was significantly high compared to that of the control group. Though the posttest was a self-reported evaluation, the participants conveyed that the program helped their competency in collaborative leadership, interprofessional communication, interprofessional conflict solving skills, understanding the roles of other professionals in interprofessional collaboration, and understanding their own roles within the collaborative practice in interprofessional collaboration. This result supports the findings of other studies that reported improvements in competency through participation in similar programs [15]. This implies that students achieved the academic objectives due to the fact that five categories of competency in this study are associated with the learning outcome the program had established. Considering the survey was conducted immediately after the program concluded, it is necessary to conduct a follow-up survey after a measurable period of time to ensure the durability of the outcome.

The results of the program satisfaction survey revealed that most of the participants were satisfied with the program. To be specific, the results indicated the program was helpful in raising the awareness of the importance of working as a team, understanding the roles and responsibilities of other health professions, and communication as well as collaboration. The participants provided positive feedback on the program regarding their opportunity to participate in discussion with students of other healthcare professions and that the primary participants of the program were students. This outcome complements the findings of previous studies [21]. It is likely that such feedback is contributed to the role-play and small-group activities, as it has been reported that interactive IPE is effective [3]. There was some negative feedback regarding the insufficient running time allotted for the program content. This limitation is due to the discrepancy in the academic timetables and curriculums, which make it challenging to offer the program in multiple sessions. This was also mentioned as a challenge for implementing IPE in other institutions [27]. In order to overcome this limitation and implement the program within a regular curriculum, schools of healthcare should actively collaborate with one another to develop complementary meeting schedules.

Suggestions can be made with regard to the following limitations in this study. The finding of this study cannot be generalized because the program was implemented as a one-day program, and the participants of this study were limited to final-year students in schools of medicine, nursing, and pharmacy. And the pre-post-test was also conducted on the same day, the test effect was not controlled. In order to overcome these limitations, it is necessary to consider qualitative analysis methods such as an analysis of reflection essays on impressions after program. It is also necessary to conduct long-term programs with several sessions. Early exposure to the IPE program can be helpful for building positive attitudes toward their profession [22,28] as the 
professional identity of professional healthcare students is typically developed during their first year of studying a particular major [29]. Designing a cumulative and continuous program with a series of sessions that begins in the first year of major study would be effectively improve the IPE competency of students. Since this study used an identical questionnaire for the pretest and the posttest, probability exists that the second test might have corrupted the result. In addition, because the posttest was conducted immediately after the program concluded, it is necessary to provide follow-up interviews at measurable intervals to analyze the long-term effect of the program [30]. Moreover, it is desirable to make diverse educational attempts by adopting web-based, simulation-based, or virtual patient approaches.

In conclusion, the participation in the IPE program was effective and valuable in improving students' perception towards IPE, self-efficacy for interprofessional experiential learning, and perception towards of interprofessional competency. The significance of this study is also that it developed an engaging IPE program for medical students, nursing students, and pharmacy students that maximizes the interaction among students of health professions by utilizing a wide range of teaching methods such as role-play and small group activities. In addition, this study analyzed the effectiveness of the program by comparing the intervention and control groups. It is hoped that this study will provide baseline data for planning and vitalizing IPE programs in other colleges.

\section{ORCID:}

Han Jung: https://orcid.org/0000-0002-8303-6441;

Kwi Hwa Park: https://orcid.org/0000-0002-0008-2400;

Yul Ha Min: https://orcid.org/0000-0002-1657-8582;
Eunhee Ji: https://orcid.org/0000-0001-8558-1032

Acknowledgements: None.

Funding: This work was supported by the Ministry of Education of the Republic of Korea and the National Research Foundation of Korea (NRF-2017S1A5A2A 01025837).

Conflicts of interest: No potential conflict of interest relevant to this article was reported.

Author contributions: Conception or design of the work: KHP; drafting the article: HJ; data collection, data analysis and interpretation: HJ, KHP, YHM, EHJ; and critical revision of the article and final approval of the version to be published: KHP.

\section{References}

1. Aston SJ, Rheault W, Arenson C, et al. Interprofessional education: a review and analysis of programs from three academic health centers. Acad Med. 2012;87(7): 949-955.

2. Buring SM, Bhushan A, Broeseker A, et al. Interprofessional education: definitions, student competencies, and guidelines for implementation. Am J Pharm Educ. 2009;73(4):59.

3. Bridges DR, Davidson RA, Odegard PS, Maki IV, Tomkowiak J. Interprofessional collaboration: three best practice models of interprofessional education. Med Educ Online. 2011;16.

4. World Health Organization. Framework for action on interprofessional education and collaborative practice. Geneva, Switzerland: World Health Organization; 2010.

5. Horsburgh M, Merry AF, Seddon M. Patient safety in an interprofessional learning environment. Med Educ. 2005; 39(5):512-513.

6. Reeves S, Freeth D, McCrorie P, Perry D. 'It teaches you what to expect in future...': interprofessional learning on 
a training ward for medical, nursing, occupational therapy and physiotherapy students. Med Educ. 2002; 36(4):337-344.

7. Lee YH, Ahn D, Moon J, Han K. Perception of interprofessional conflicts and interprofessional education by doctors and nurses. Korean J Med Educ. 2014;26(4):257-264.

8. Hammick M, Freeth D, Koppel I, Reeves S, Barr H. A best evidence systematic review of interprofessional education: BEME guide no. 9. Med Teach. 2007; 29(8):735-751.

9. Schmitt MH, Gilbert JH, Brandt BF, Weinstein RS. The coming of age for interprofessional education and practice. Am J Med. 2013;126(4):284-288.

10. West C, Graham L, Palmer RT, et al. Implementation of interprofessional education (IPE) in 16 U.S. medical schools: common practices, barriers and facilitators. J Interprof Educ Pract. 2016;4:41-49.

11. Blue AV, Zoller J, Stratton TD, Elam CL, Gilbert J. Interprofessional education in US medical schools. J Interprof Care. 2010;24(2):204-206.

12. Kim S. Perceptions and attitudes towards interprofessional education in medical schools. Korean Med Educ Rev. 2017;19(1):10-17.

13. Kim KH, Hwang E, Shin S. Current status and future direction of interprofessional education in nursing education. Korean Med Educ Rev. 2017;19(1):18-24.

14. Yune SJ, Park KH, Min YH, Ji E. Perceptions of the interprofessional education of the faculty and the level of interprofessional education competence of the students perceived by the faculty: a comparative study of medicine, nursing, and pharmacy. Korean J Med Educ. 2020;32(1):23-33.

15. Hwang JI, Yoon TY, Jin HJ, Park Y, Park JY, Lee BJ. Patient safety competence for final-year health professional students: perceptions of effectiveness of an interprofessional education course. J Interprof Care.
2016;30(6):732-738.

16. Guinan EM, Barrett EM, Neill F, et al. Attitudes to interprofessional education among health science students engaging in a multidisciplinary workshop series. Int J Health Sci Educ. 2018;5(1):2.

17. Lestari E, Stalmeijer RE, Widyandana D, Scherpbier A. Understanding students' readiness for interprofessional learning in an Asian context: a mixed-methods study. BMC Med Educ. 2016;16:179.

18. Baek SY, Yun SJ, Kam B, Lee SY, Woo JS, Im SJ. The role of the teaching hospital in the effective clerkship. Korean Med Educ Rev. 2015;17(1):5-9.

19. McFadyen AK, Webster V, Strachan K, Figgins E, Brown $\mathrm{H}$, McKechnie J. The Readiness for Interprofessional Learning Scale: a possible more stable sub-scale model for the original version of RIPLS. J Interprof Care. 2005; 19(6):595-603.

20. Mann K, McFetridge-Durdle J, Breau L, et al. Development of a scale to measure health professions students' self-efficacy beliefs in interprofessional learning. J Interprof Care. 2012;26(2):92-99.

21. Zeeni N, Zeenny R, Hasbini-Danawi T, et al. Student perceptions towards interprofessional education: findings from a longitudinal study based in a Middle Eastern university. J Interprof Care. 2016;30(2):165-174.

22. Ruebling I, Pole D, Breitbach AP, et al. A comparison of student attitudes and perceptions before and after an introductory interprofessional education experience. J Interprof Care. 2014;28(1):23-27.

23. Delunas LR, Rouse S. Nursing and medical student attitudes about communication and collaboration before and after an interprofessional education experience. Nurs Educ Perspect. 2014;35(2):100-105.

24. Ivey CK, Bowman DH, Lockeman KS. Changes in physical and occupational therapy students' self-efficacy using an interprofessional case-based educational experience. J Phys Ther Educ. 2018;32(2):199-205. 
25. Chang MJ, Cho E, Noh H, Lee JI. Studies on the perception on clinical pharmaceutical care and clinical pharmaceutical sciences. Korean J Clin Pharm. 2014; 24(3):169-182.

26. Bolesta S, Chmil JV. Interprofessional education among student health professionals using human patient simulation. Am J Pharm Educ. 2014;78(5):94.

27. Liston BW, Fischer MA, Way DP, Torre D, Papp KK. Interprofessional education in the internal medicine clerkship: results from a national survey. Acad Med. 2011;86(7):872-876.
28. Osman A. What makes medical students receptive to interprofessional education?: findings from an exploratory case study. J Interprof Care. 2017;31(5):673-676.

29. Ateah CA, Snow W, Wener P, et al. Stereotyping as a barrier to collaboration: does interprofessional education make a difference? Nurse Educ Today. 2011;31(2): 208-213.

30. Olson R, Bialocerkowski A. Interprofessional education in allied health: a systematic review. Med Educ. 2014;48(3):236-246. 